Available online on 15.04.2020 at http://jddtonline.info
Open Access to Pharmaceutical and Medical Research
unrestricted non-commercial use, provided the original work is properly cited

Open $\odot$ Access

Research Article

\title{
Preparation and Characterization of Celecoxib Entrapped Guar Gum Nanoparticles Targeted for Oral Drug Delivery against Colon Cancer: An In- Vitro Study
}

\author{
Chandel Deepika', Uppal Shivani², Mehta Surinder Kumar², Shukla Geeta ${ }^{1 *}$ \\ ${ }^{1}$ Department of Microbiology, Basic Medical Sciences Block I, South Campus, Sector 25, Panjab University, Chandigarh 160014, India \\ 2 Department of Chemistry \& Centre of Advanced Studies in Chemistry, Panjab University, Chandigarh 160014, India
}

\begin{abstract}
The present study is an attempt to synthesize nanosized guar gum carriers encapsulating celecoxib as the chemopreventive agent for experimental colorectal cancer (CRC). Guar gum nanoparticles without celecoxib (eGGNPs) and celecoxib loaded guar gum nanoparticles (cGGNPs) were prepared by oil-in-water emulsification and in situ polymer crosslinking method. Electron microscopy, zeta potential and fourier transform infrared spectra analysis was used to affirm the size, stability and morphology of the nanoparticles. In-vitro drug release was investigated using dialysis method. Further, the effect of nanoparticles (eGGNPs \& cGGNPs) was evaluated on Caco 2 colon cancer cell lines. Spherical guar gum nanoparticles were obtained in the size range of $200 \pm 6 \mathrm{~nm}$ with zeta potential of $-32.1 \mathrm{mV}$ indicating good stability of the GGNPs with drug loading of $30 \pm 3.2 \%$, and drug release following zero order kinetics. The eGGNPs had no effect on Caco 2 cell viability whereas the cGGNPs showed time and concentration dependent growth inhibition of Caco 2 cells. These findings suggest the successful preparation of chemopreventive nanoparticles that can be targeted as the prophylactic agent for experimental colorectal cancer.
\end{abstract}

Keywords: nanoparticles, guar gum, celecoxib, colorectal cancer, release kinetics, cytotoxicity

Article Info: Received 23 Jan 2020; Review Completed 19 March 2020; Accepted 23 March 2020; Available online 15 April 2020

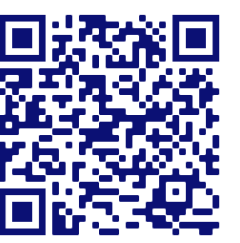

\section{Cite this article as:}

Chandel D, Uppal S, Mehta SK, Shukla G, Preparation and Characterization of Celecoxib Entrapped Guar Gum Nanoparticles Targeted for Oral Drug Delivery against Colon Cancer: An In-Vitro Study, Journal of Drug Delivery and Therapeutics. 2020; 10(2-s):14-21 http://dx.doi.org/10.22270/jddt.v10i2-s.3951

*Address for Correspondence:

Prof. Geeta Shukla, Department of Microbiology, Basic Medical Sciences Block I, Panjab University, Sector 25, Chandigarh, 160 014, India

\section{INTRODUCTION}

Colorectal cancer is the third most common cancer worldwide and is one of the leading causes of mortality ${ }^{1}$. Genetic and environmental factors such as poor diet, lack of exercise, obesity, smoking and alcohol intake are thought to increase the risk of developing colorectal cancer ${ }^{2}$. More than $60 \%$ of cancer deaths occur in underdeveloped and developing countries, many of which lack the medical resources and health systems to support the disease burden 3 . In India too an increase in CRC incidence rates has been observed in the past decade due to change in lifestyle and $\operatorname{diet}^{4,5}$. Additionally, economic transition from a low to middle income economy has increased the burden of CRC in India emphasizing the need to prevent or reduce the occurrence of CRC, a life style disease, particularly in high risk individuals 6 .

A body of evidence indicates the role of inflammation in the development of cancer progression, designating it as the seventh hall mark of cancer ${ }^{7}$. Among the different mediators of inflammation, the cyclo-oxygenases belonging to the family of myleoperoxidases, also known as prostaglandin $\mathrm{H}$ synthases appear to be implicated in cancer. Prostaglandinendoperoxidse synthase 2 (COX-2) modulates cell proliferation, cell death and tumor invasion ${ }^{8}$. Targeting these enzymes has been attempted to reduce inflammation and progression of polyps. Specifically, clinical observations and case series studies have demonstrated that celecoxib, the COX-2 selective inhibitor, reduced the adenomatous polyp burden among patients with familial adenomatous polyposis $9,10,11,12$. Celecoxib possesses anti-inflammatory and anti-tumorigenic efficacy and has been clinically approved by FDA for familial adenomatous polyposis (FAP) patients ${ }^{13,14}$. Though effective, however, these drugs are not recommended for long term therapy or in high doses due to associated adverse effects such as cardiovascular toxicity, myocardial infarction, gastrointestinal toxicity, renal toxicity and mucosal damage 15,16 . To overcome the off target drug toxicity, nanoparticles (NPs) have piqued the interest of the medical community for use in cancer diagnosis, prevention, treatment and as delivery vectors for biologic or pharmacologic agents. Due to small particle size, they are attracted to their target tissues and have the advantages of targeted drug delivery to the desired site of action, 
prolonged blood circulation of the encapsulated drug, and reduced drug side effects thus nanoparticle encapsulated drugs are preferred 17,18 .

Biodegradable materials for nanoparticles such as polysaccharides are gaining considerable attention due to biocompatibility due to enhanced bio-adhesion with biological tissues, like epithelia and mucous membranes, non toxicity, abundant resources in nature and low cost in their processing ${ }^{19}$. Guar galactomannan commonly known as guar gum, a water soluble polysaccharide extracted from the seeds of Cyamopsis tetragonoloba, has been extensively used for delivery to colon due to its drug release retarding property and susceptibility to microbial degradation in large intestine ${ }^{20,21}$. Additionally, guar gum also has prebiotic properties i.e. it acts as a non-digestible food ingredient that beneficially affects the host by selectively stimulating the growth and/or activity of one or a limited number of bacteria in the colon, and thus improves host health ${ }^{22}$. Guar gum has been extensively studied for preparation of tablet coatings to achieve colon specific delivery ${ }^{23}$. More specifically, several nanoparticle formulations have been reported for the delivery of anticancer drugs such as 5Flourouracil, methotrexate etc. using guar gum against breast cancer, esophageal cancer among others $24,25,26$. Though, guar gum based nanosized materials have been used as drug delivery agent but literature pertaining to its use as prophylactic drug carriers for CRC is not available. Therefore, the present study aimed at preparing guar gum nanoparticles encapsulating celecoxib to be used as a targeted drug delivery system to the colon cancer as an effective prophylactic agent.

\section{MATERIALS AND METHODS}

\subsection{Materials}

HPLC grade Di-chloromethane (DCM) and Glutaraldehyde (25\%) were purchased from Merck Chemicals, Mumbai India. Guar gum powder, Span80, HPLC grade water and Glycerol were purchased from HiMedia Laboratories, Mumbai, India. Celecoxib was a gift from Ind Swift Laboratories Limited, Punjab, India.

\subsection{Preparation of guar gum nanoparticles (GGNPs)}

Celecoxib loaded guar gum nanoparticles (cGGNPs) as well as empty guar gum nanoparticles (eGGNPs) were prepared by oil in water emulsification and in situ polymer crosslinking method with slight modifications ${ }^{27}$. Briefly, $10 \mathrm{mg}$ celecoxib was dissolved in $10 \mathrm{~mL}$ DCM (DCM without celecoxib for eGGNPs) and $1 \mathrm{~mL}$ Span $80(2 \% \mathrm{v} / \mathrm{v})$ was added to make oil phase. $30 \mathrm{~mL}$ of $0.5 \%$ aqueous guar gum solution was kept under constant magnetic stirring to which the oil phase was then added drop-wise. After mutual saturation of the oil and the continuous phase, the mixture was sonicated for 10 minutes (30s 0n/10s Off, 40\% amplitude) followed by drop-wise addition of $10 \mathrm{~mL}$ glycerol. Thereafter, $1 \mathrm{~mL}$ gluteraldehyde $(25 \%)$ was then added as crosslinker. Nanosuspension thus obtained was kept overnight at $37^{\circ} \mathrm{C}$ for nanoparticle formation. Nanoparticles were obtained after cold centrifugation at 20,000 rpm for $30 \mathrm{~min}$, washed with $15 \mathrm{~mL}$ HPLC grade water and re-centrifuged. The yielded nanoparticles were lyophilized, harvested in micro centrifuge tubes and preserved in vacuum desiccator.

\subsection{Characterization}

\subsubsection{Particle size and zeta potential analysis}

The particle size of the formulations was determined using Malvern Zeta Nano S 90 (Malvern Instruments, Malvern, UK) that works on the principle of dynamic light scattering (DLS) analyzing the Brownian motion of the colloidal particles. It measures the hydrodynamic diameter and poly dispersity index (PDI) ${ }^{28,29}$. DLS measurements were conducted with $1 \mathrm{mg} / \mathrm{ml}$ of particle emulsions in Millipore water. Measurements were performed in triplicate at $90^{\circ}$ angle and samples were maintained at $25^{\circ} \mathrm{C}$. Zeta potential was estimated on the basis of electrophoretic mobility under an electrical field using Malvern zeta potential (Nano Sight NS500) at $25^{\circ} \mathrm{C}$.

\subsubsection{Scanning and Transmission electron microscopy}

The size, shape and morphology of the prepared GGNP's were analysed using Transmission electron microscopy (TEM) and field emission scanning electron microscopy (FESEM).

Briefly, the sample was dried properly and kept in vacuum desiccator overnight prior to sample preparation. After drying, the sample was fixed on carbon coated tap placed in an aluminium stub mounted in a sputter coater unit for gold sputtering run for $30 \mathrm{~s}$ and scanning was performed in secondary electron mode at voltage $5 \mathrm{kV}$.

A drop of water suspension of the GGNPs was mounted on a carbon coated copper grid (CCG), air-dried and stained with uranyl acetate and lead citrate and examined at $80 \mathrm{kV}$ accelerating voltage at JEOL Transmission Electron Microscope, JEM-1400Plus (JEOL, Tokyo, Japan) equipped with XR81M-B Camera (Advanced Microscopy Techniques Corp, Woburn, MA, United States). Digital electron micrographs were acquired using AMT Image Capture Engine V602 software (Advanced Microscopy Techniques Corp, Woburn, MA, United States).

\subsubsection{Fourier transform infrared spectroscopy}

FTIR spectra of pure celecoxib, guar gum, eGGNP's and cGGNPs were recorded to observe for any drug-polymer interaction. FTIR spectrum was recorded with thermallycontrolled diode laser in the spectral region of 4000-500 cm 1 using thermo scientific, Nicolet iS50 FT-IR.

\subsubsection{X-ray Diffraction}

Powder X ray diffraction (XRD) studies were carried out using Brukner D8 Advance X-ray diffractomer equipped with $\mathrm{Cu}-\mathrm{K} \alpha$ radiation source $(\lambda=1.541 \mathrm{~A})$ and step size of $0.015^{\circ}$ under the accelerating voltage of $40 \mathrm{kV}$ and $25 \mathrm{~mA}$.

\subsection{Drug loading and In-vitro drug release}

A stock solution of celecoxib was prepared for standard curve as described earlier ${ }^{30}$. The $\lambda$ max of celecoxib was determined by scanning suitable dilution of stock. The drug loading of celecoxib in nanoparticles was determined by dissolving drug loaded-NP's (5mg) in 1:1 ratio of DMSO:deionised water $(5 \mathrm{ml})$. Samples were rotated for $24 \mathrm{~h}$ at $50 \mathrm{rpm}$ to ensure complete dissolution. eGGNPs were treated identically. The concentration of celecoxib in resulting solution was determined by measuring absorbance at $252 \mathrm{~nm}$ with spectrophotometer using eGGNPs as blank solution. All samples were analyzed in triplicate. Drug loading percentage was calculated as below:

Drug loading $(\%)=$ (Weight of celecoxib loaded in NPs $/$ Weight of NPs) $\times 100$

Dialysis technique was adopted to carry out the release experiments. Celecoxib release profiles were determined by suspending drug loaded NPs $(20 \mathrm{mg})$ in PBS $(2 \mathrm{ml})$ at $\mathrm{pH} 7.4$ and poured in the dialysis bag $(5 \mathrm{kDa}) .100 \mathrm{ml}$ bath fluid (PBS; pH 7.4) incubated at $37 \circ \mathrm{C}$ while magnetic stirring at $50 \mathrm{rpm}$ was used. The released media was removed and replaced with fresh buffer. The concentration of celecoxib in 
the release media was determined using the UV detection method described above. The absorption of supernatant collected from blank NPs was subtracted from absorption of supernatant collected from loaded NP's.

\subsubsection{Kinetics of drug release}

The cumulative amount of celecoxib released from GGNPs at different time intervals were fitted to zero order kinetics using Least Squares Method of analysis to find out whether the drug release from the formulations is providing a constant drug release. The data were further fitted to first order kinetics ${ }^{31}$, Higuchi model ${ }^{32}$ and Power law model ${ }^{33}$ to find out the drug release mechanism from the formulations. The percent of drug released from the formulations was plotted against time on log-log scale, and analyzed for linearity using Least Squares Method. The regression coefficients were calculated and used to find the fitness of the data. To analyze the drug release kinetics and mechanism, data were analysed using the following four models i.e Zero order, $\mathrm{D}_{\mathrm{t}}=\mathrm{k}_{\mathrm{o}} \cdot \mathrm{t}$; First Order, $\mathrm{Q}_{\mathrm{t}}=\mathrm{Q}_{0} \mathrm{e}^{-\mathrm{kt}}$; Higuchi Model, $Q_{t}=K_{H} \sqrt{t}$; Power Law Model, $D_{t}=D_{\alpha} \cdot k_{p} t^{n}$. Where $D_{t}$ represents amount of drug released at time $t$ and $\mathrm{k}_{0}, \mathrm{k}_{1}, \mathrm{k}_{\mathrm{H}}, \mathrm{k}_{\mathrm{p}}$ represents zero order release constant, first order release constant, Higuchi constant and KorsemeyerPeppas constant respectively; $Q$ is the cumulative amount of drug released in time $t, D_{t}$ is the amount of drug released in time $t, D_{\alpha}$ is the amount of drug released after time $\alpha ; n$ is an exponent that characterizes the diffusional release kinetic mechanism in the Power law model. The data were analyzed for initial $50 \%$ release only. The values of regression coefficients $\left(\mathrm{R}^{2}\right)$ were determined by fitting the release data into respective equations.

\subsubsection{In vitro cytotoxicity measurements}

To assess the cytotoxicity of GGNPs (loaded and blank) MTT assay was employed as per Mossmann et al., 200034. Caco-2 cell line, procured from Cell repository, National Centre for Cell Sciences, Pune, India, was maintained in Minimum essential medium supplemented with penicillin $10 \mathrm{U} / \mathrm{mL}$, Streptomycin $100 \mu \mathrm{g} / \mathrm{mL}$ and $20 \%$ heat inactivated FBS, by incubating at $37^{\circ} \mathrm{C}$ in a humidified atmosphere with $5 \% \mathrm{v} / \mathrm{v}$ $\mathrm{CO}_{2}$ in carbon dioxide incubator. Caco 2 cells were seeded $\left(10^{5}\right.$ cells $\left./ \mathrm{ml}\right)$ into 96 -well plate and allowed to incubate for 24h.Thereafter, the media was changed with fresh growth media. Both blank as well as celecoxib loaded GGNPs $(20 \mu \mathrm{L})$ in different concentration $(0.1,0.2,0.3,0.4,0.5,0.6$, and
$1 \mathrm{mg} / \mathrm{ml}$ ) were added to each well and incubated with the cells for $24,48,72 \mathrm{~h}$. After respective time interval of treatment, $20 \mu \mathrm{L}$ of MTT reagent $(5 \mathrm{mg} / \mathrm{mL})$ was added to each well and incubated for $4 \mathrm{~h}$. Thereafter, media was removed completely and DMSO $(150 \mu \mathrm{l})$ was added to each well to dissolve the formazan crystals. Absorbance was measured at $570 \mathrm{~nm}$ using ELISA reader (TECAN Infinite M200). Results were expressed in terms of \%survival of cells with treatment to that of untreated cells and were calculated as (OD of test/OD of control) $\times 100$. All tests were performed in triplicate and repeated thrice.

\section{RESULTS}

\subsection{Guar gum nanoparticles preparation}

It was observed that mean particle diameter decreased from $511 \mathrm{~nm}$ to $200 \mathrm{~nm}$ with varying sonication time from 0 to 10 minutes. The increase in the sonication time also decreased the poly disparity index of the solution making it more homogenous. $10 \mathrm{~min}$ sonication of the formulation resulted in nanoparticles of $200 \pm 6.89 \mathrm{~nm}$ size with pDI of 0.058 (Table 1).

Table 1: Effect of sonication time on size of GGNP's. Values are mean $\pm S D$.

\begin{tabular}{|c|c|c|}
\hline Sonication time & Average size & Average pDI \\
\hline 0 & $511 \pm 10.43$ & $1.3 \pm 0.370$ \\
\hline 2 & $416 \pm 17.35$ & $1.19 \pm 0.269$ \\
\hline 4 & $353 \pm 17.35$ & $0.45 \pm 0.127$ \\
\hline 6 & $293 \pm 34.96$ & $0.315 \pm 0.130$ \\
\hline 8 & $218 \pm 34.96$ & $0.216 \pm 0.0393$ \\
\hline 10 & $200 \pm 6.89$ & $0.058 \pm 0.0269$ \\
\hline
\end{tabular}

\subsection{Characterization}

\subsubsection{Particle size and zeta potential analysis}

The mean particle size of empty as well as celecoxib loaded GGNPs was $200 \pm 6 \mathrm{~nm}$ with narrow range size distribution and low poly dispersity index values $(<0.1$.) as measured by DLS method. The $\zeta$ potential of eGGNPs was $-35.9 \mathrm{mV}$ whereas that of cGGNPs was $-32.1 \mathrm{mV}$ (Figure 1).
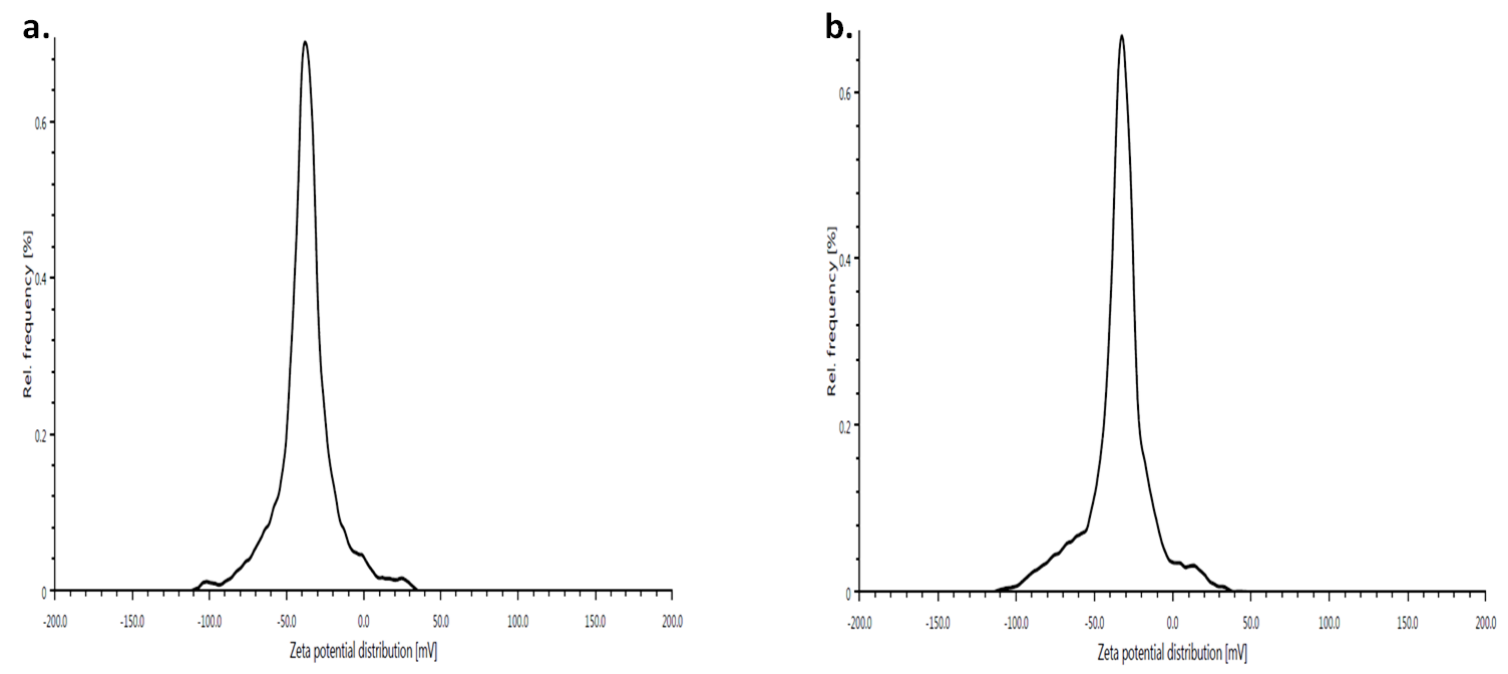

Figure 1: Zeta potential of (a) eGGNPs and (b) cGGNPs 


\subsubsection{Field emission scanning electron microscopy and Transmission electron microscopy}

The surface morphology and internal structure was monitored using FESEM and TEM and it was interesting to observe that the prepared nanoparticles possessed nearly smooth surface and spherical shape (Figure 2). Transmission electron microscopy image of GGNPs also showed spherical particles of 100-200 nm size with capsular structures and homogenous shells (Figure 3). Most of the particles appeared small, individual and distinct but the appearance of some large particles was due to aggregation of smaller particles.

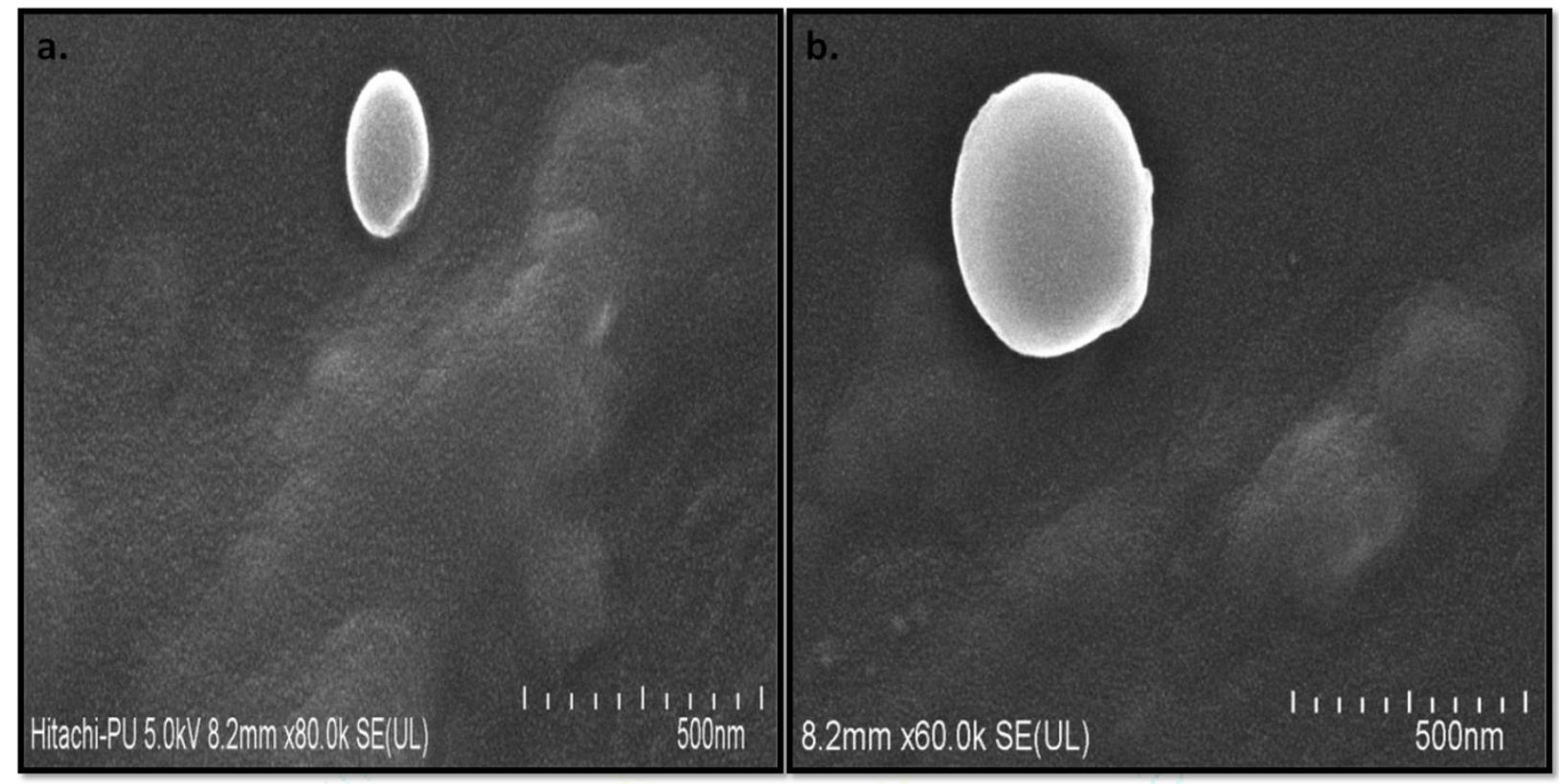

Figure 2: FESEM images illustrating morphology of (a) eGGNP; (b) cGGNP.

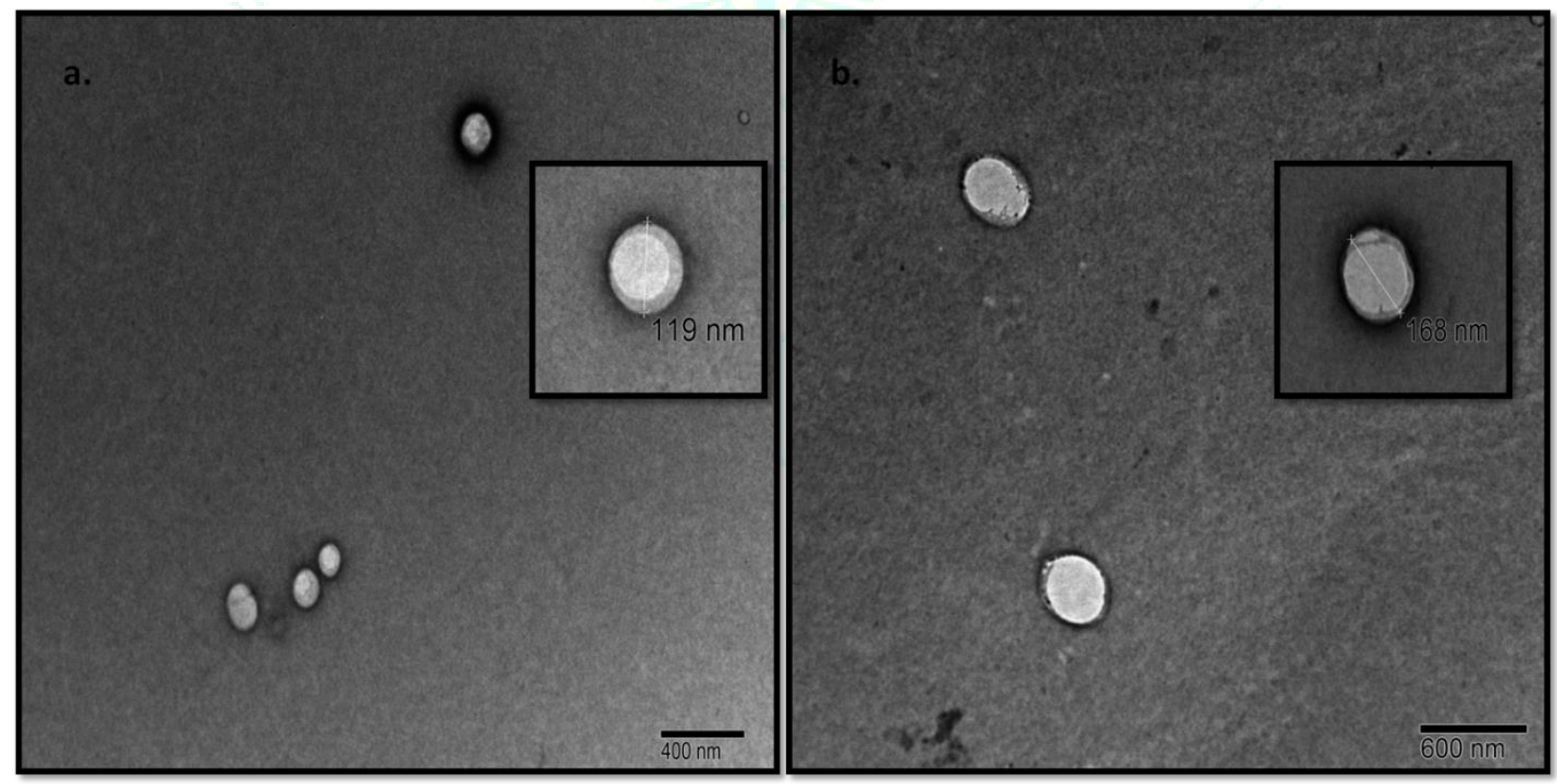

Figure 3: TEM micrograph of (a) eGGNPs; (b) cGGNP's.

\subsubsection{Fourier transform infrared spectroscopic analysis}

FTIR spectra of Guar gum, Celecoxib, eGGNPs and cGGNPs were recorded to compare the changes in their chemical structure and to study the drug polymer interactions. There was no appearance or disappearance of peaks in the formulation when compared with guar gum spectra, which confirmed the absence of chemical interaction between drug and polymer. The region of FTIR spectra between 3000 and $2800 \mathrm{~cm}-1$ shows $\mathrm{C} \mathrm{H}$ stretching modes. It was observed that two distinct prominent peaks were present in blank as well as loaded nanoparticles but not in guar gum indicating successful in-situ crosslinking (Figure 4). 

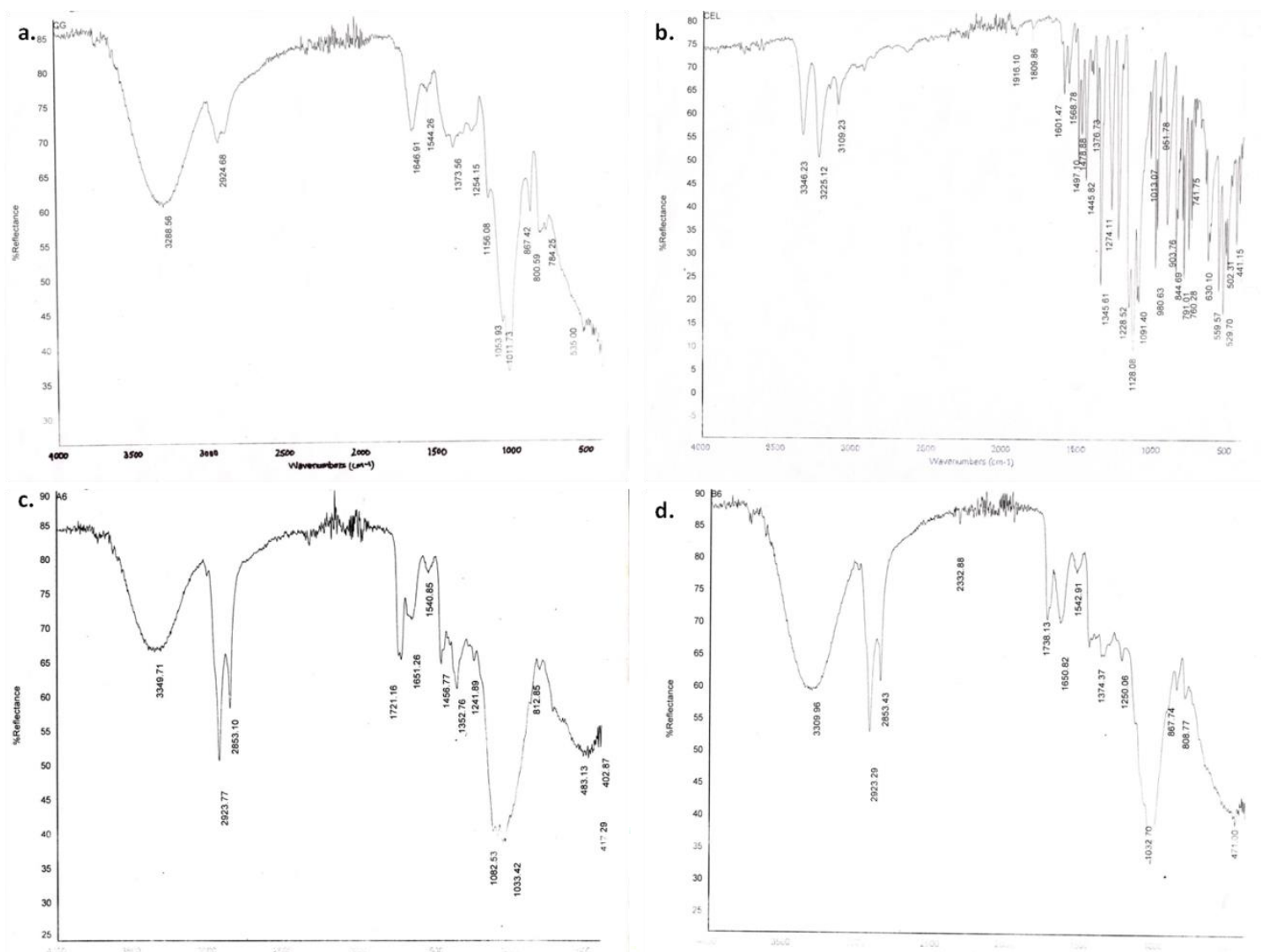

Figure 4: FTIR Spectra of (a) Guar gum; (b) Celecoxib; (c) eGGNP's; and (d) cGGNP's.

\subsubsection{Wide angle $X$-ray diffraction}

The X-ray diffraction (XRD) pattern of empty guar gum nanoparticles and Celecoxib loaded guar gum nanoparticles revealed that empty GGNP's had amorphous structure while encapsulation of celecoxib resulted in slight increase in crytallinity in cGGNPs as a small peak was observed around $20 \boldsymbol{\theta}$ (Figure 5).

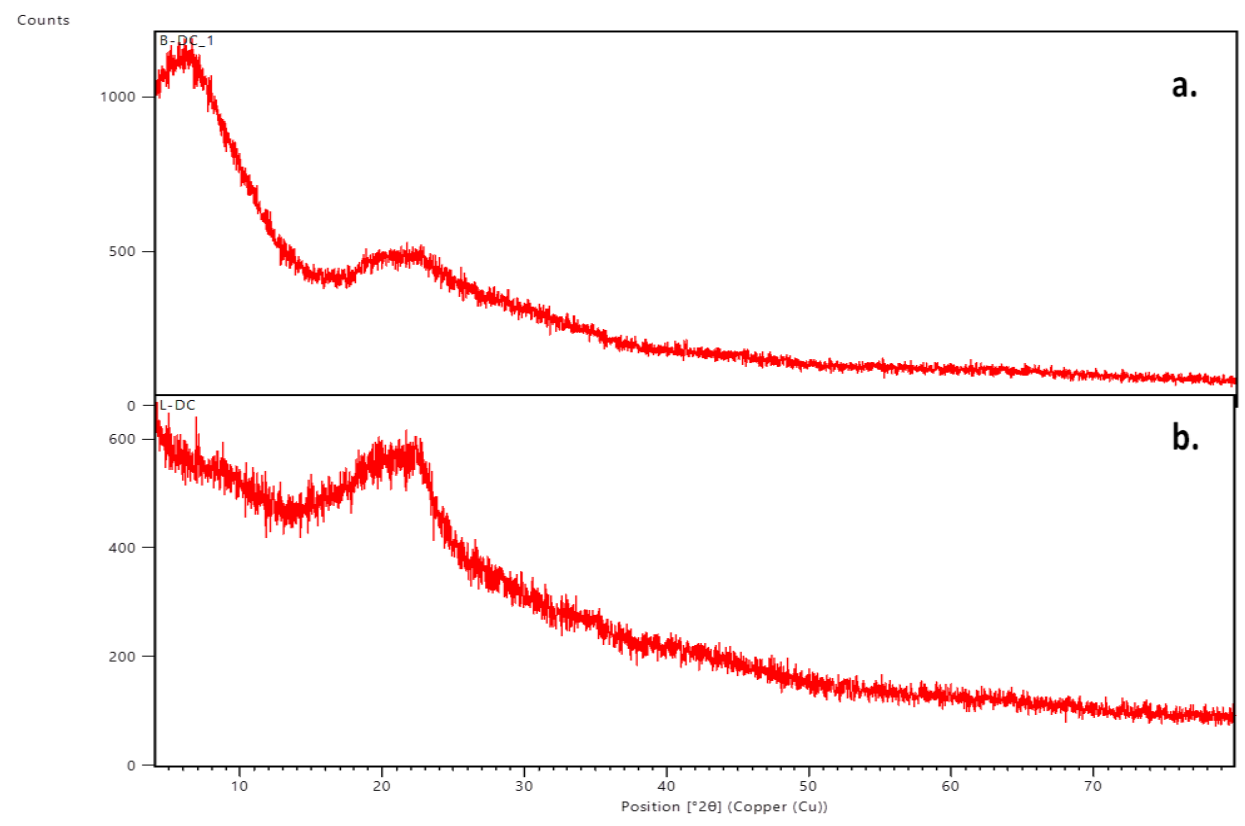

Figure 5. XRD spectra of (a) eGGNP's and (b) cGGNPs. 


\subsection{Drug loading and drug release in vitro}

The loading capacity is the amount of drug loaded in the nanoparticles and it was $30 \% \pm 3.2$ in cGGNP's. Further, the time dependent cumulative release profile of cGGNPs was analyzed for a period of $22 \mathrm{~h}$. The release data was fitted into four kinetic models (Figure 6). Based on regression coefficient analysis $\mathrm{R}^{2}$ was highest for power law model followed by Zero order model but the value of slope was close to unity for Power law model. Thus, it was concluded that the release followed time dependent Zero order kinetics (Table 2).
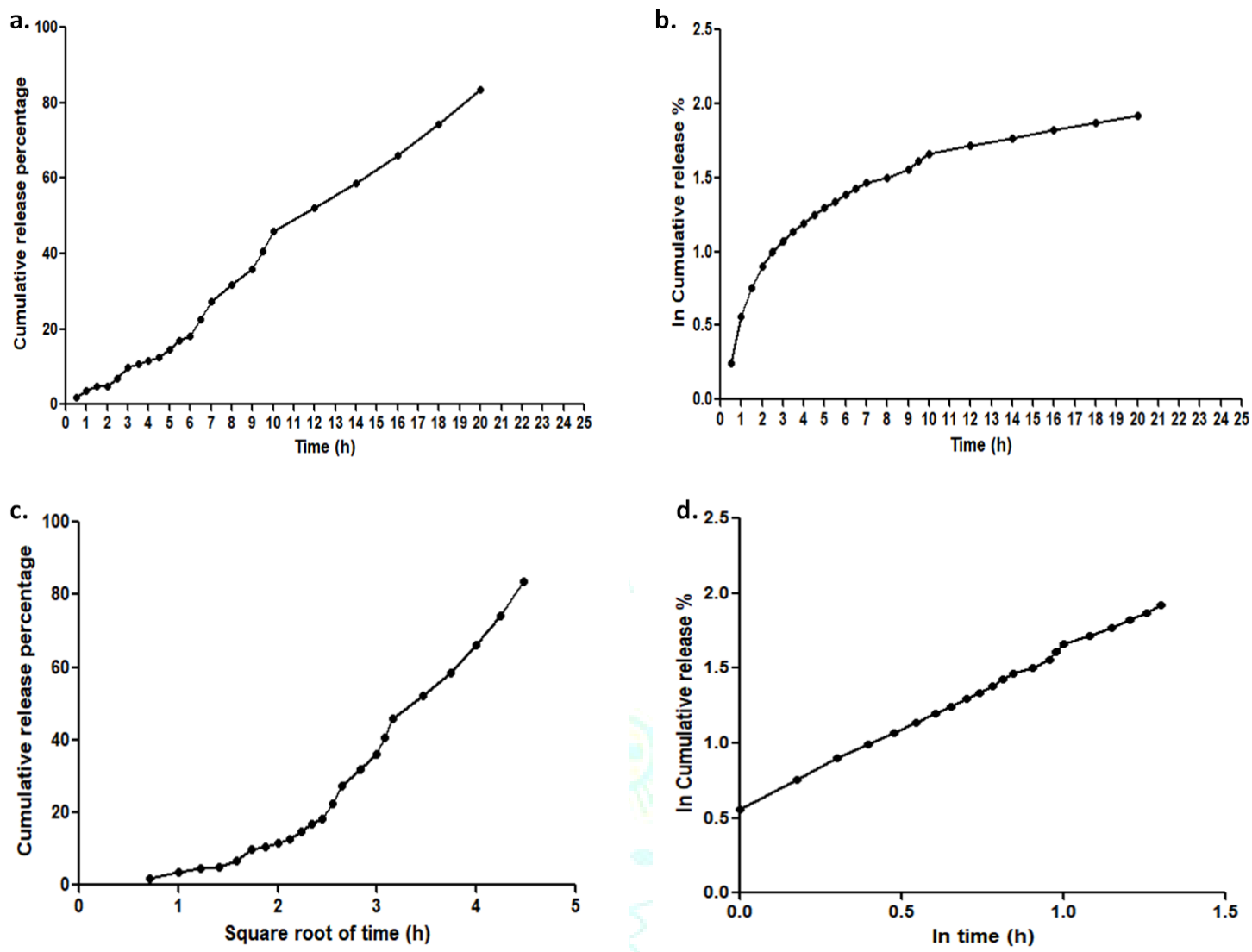

Figure 6: (a-d) Zero order, First order, Higuchi model, Power Law model of cumulative release percentage of celecoxib from cGGNPs.

Table 2. Regression coefficient (R2) for cGGNP's after fitting in the in-vitro drug release data to four different mathematical models of drug release kinetics.

\begin{tabular}{|l|l|l|l|}
\hline $\mathbf{R}^{2}$ Zero order & $\mathbf{R}^{2}$ First order & $\mathbf{R}^{2}$ Higuchi model & $\mathbf{R}^{2}$ Power Law model \\
\hline 0.9890 & 0.7895 & 0.9325 & 0.9985 (Slope 1.02) \\
\hline
\end{tabular}

\subsection{Cytotoxicity assay}

The effect of eGGNPs as well as cGGNP's on growth of colon cancer cell line Caco-2 was evaluated. Since biocompatibility and safety of guar gum nanoparticles is a prerequisite for its clinical use, eGGNP's were evaluated for any toxicity against Caco-2 cell line and it was interesting to observe that eGGNP's had no effect on viability of Caco-2 cells. Whereas, cGGNP's inhibited the growth of Caco-2 cells in a time and concentration dependent manner but the growth inhibition was less compared with pure celecoxib (Figure 7).

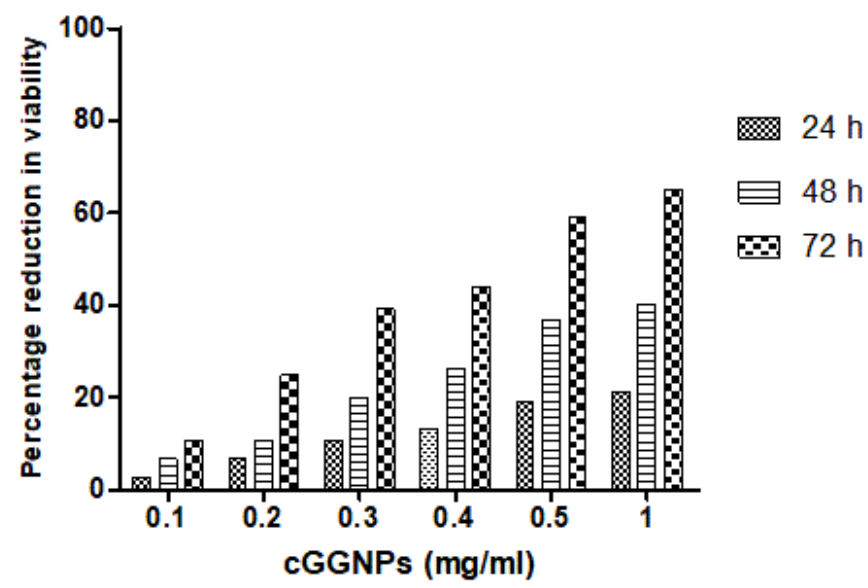

Figure 7: Effect of cGGNP's on viability of Caco-2 cell line. 


\section{DISCUSSION}

Colorectal cancer, a lifestyle disease, is a leading health problem globally. Chemopreventive agents such as nonsteroidal anti-inflammatory drugs (Celecoxib, Sulindac, Aspirin) are an attractive alternate which can be developed into potent prophylactic agents. Major limitations in NSAID use for chemoprevention are the side effects associated with high doses and long term use. Biodegradable nanoparticles have the ability to overcome such limitations as they offer targeted delivery of drug, enhanced penetration and biocompatibility. Therefore, an attempt was made to encapsulate celecoxib in guar gum nanoparticles for colon specific delivery. In the present study, celecoxib loaded guar gum nanoparticles were successfully prepared by oil in water emulsion in-situ polymer crosslinking technique. The composition of emulsion was kept constant as reported by Sarmah et al., 200927 but the sonication time was varied to check the effect of sonication time on particle size. The increase in the sonication time not only decreased the size of the particles but also decreased the poly disparity index of the solution making it more homogenous and hence more suitable for drug delivery. The nanoparticles were characterized by DLS, TEM and FESEM, which confirmed nanosized particles with smooth spherical shape and homogeneous distribution which corroborates with earlier studies 25 . These scientists have also prepared guar gum nanoparticles in similar size range and similar morphology. Further, a high $\zeta$ potential, either positive or negative, is generally required to ensure stability. In general, systems with $\zeta$ potential $> \pm 30 \mathrm{mV}$ are considered pharmaceutically stable because of particle-particle repulsion (i.e., aggregation is avoided), whereas particles between -10 and $+10 \mathrm{mV}$ are considered approximately neutral ${ }^{35}$. The $\zeta$ potential of both eGGNPs and cGGNPs was higher than $-30 \mathrm{mV}$ indicating moderate stability of the formulation. Additionally, the drug polymer interactions were analyzed by FTIR spectroscopy and the absence of drug-polymer interactions were confirmed as there was no appearance or disappearance of peaks in eGGNPs compared with cGGNPs. Further, the XRD spectra revealed that the encapsulation of celecoxib resulted in slight increase in crystallinity of the nanoparticles. The results are in agreement with earlier reports by Mudgill et al., $2012^{36}$ where they have analyzed the FTIR spectra and XRD pattern of guar gum.

Sarmah et al., $2011^{25}$ have reported that best loading of tamoxifen citrate was achieved by using DCM as drug loading solvent. Celecoxib also showed good solubility in DCM therefore, DCM was used as drug loading solvent that resulted in moderate drug loading in GGNP's. Further, the release profile of celecoxib from nanoparticles indicated delayed release, a suitable characteristic for colon specific delivery using oral route of administration. It can also be concluded from the release kinetics that the drug release is independent of amount of drug entrapped in the nanoparticles but is due to opening of polymeric chain due to swelling. Additionally, erosion of polymeric chain can also be a factor in the release of the drug. Similar results have been reported by Sarmah et al, $2011^{25}$ where guar gum nanoparticles prepared by similar technique followed zero order kinetics of drug release.

The safety analysis of GGNP's on Caco 2 cells showed that the eGGNP's did not affect the viability of Caco-2 cells indicating that the nanoparticles were non-toxic and safe to use. Furthermore, the celecoxib loaded nanoparticles were less effective than free drug in reducing the viability of Caco-2 cells that may be attributed to the fact that nanoparticles release drug slowly and colonic microbiota degrades the polysaccharide chain thereby releasing the drug but in absence of these factors drug remains inside nanoparticles and had limited effect on the viability of cells. These results suggest that due to encapsulation of drug in guar gum matrix its availability is decreased, release of drug from cGGNP's is delayed leading to lower inhibitory potential of cGGNP's compared with pure celecoxib. Moreover, in vitro cell culture model is likely to be incapable of exhibiting inhibition of cell viability under these conditions, since drug exposure and uptake is not a limiting factor in this model.

\section{CONCLUSION}

Spherical nanoparticles of guar gum encapsulating celecoxib were successfully prepared by oil-in-water emulsification and in situ polymer crosslinking method. Delayed release of drug from nanoparticles following Zero order kinetics was observed. It clearly demonstrated that the nanoparticles are capable of retarding the rate of release of celecoxib and increase in the residual time until it reaches the colon, where microbial degradation of guar gum may help in the release of drug from nanoparticles. Further, the safety of guar gum nanoparticles was established thereby making it an ideal candidate for targeted delivery of chemopreventive drug celecoxib against colon cancer in highly susceptible individuals.

\section{Acknowledgements}

Financial Support from University Grants Commission (UGC), India, is highly acknowledged.

\section{Conflict of Interest}

The authors declare no conflict of interest.

\section{REFERENCES}

1. Bray F, Ferlay J, Soerjomataram I, Siegel RL, Torre LA, Jemal A. Global Cancer Statistics 2018: GLOBOCAN Estimates of Incidence and Mortality Worldwide for 36 Cancers in 185 Countries. CA Cancer J Clin 2018; 0:1-31. doi: 10.3322/caac. 21492 .

2. Cooper K, Squires H, Carroll C, Papaioannou D, Booth A, Logan RF, Maguire C, et al. Chemoprevention of colorectal cancer: systematic review and economic evaluation. Health and Technology Assessment 2010; 14(32):1-206.

3. American Cancer Society. Cancer Facts \& Figures 2018. Atlanta: American Cancer Society (2018).

4. Yeole BB. Trends in cancer incidence in esophagus, stomach, colon, rectum and liver in males in India. Asian Pac J Cancer Prev. 2008; 9:97-100.

5. NCRP. Three-year report of the population based cancer registries- 2009-2011. National cancer registry programme, Indian council of medical research (ICMR), Bangalore, India. 2013.

6. Mohandas KM. Colorectal cancer in India: controversies, enigmas and primary prevention. Indian J Gastroenterol. 2011; 30(1):36. doi: 10.1007/s12664-010-0076-2.

7. Colotta F, Allavena P, Sica A, Garlanda C, Mantovani A. Cancerrelated inflammation, the seventh hallmark of cancer: links to genetic instability. Carcinogenesis. 2009; 30(7):1073-81. doi: 10.1093/carcin/bgp127.

8. Sobolewski C, Cerella C, Dicato M, Ghibelli L, and Diederich M. The role of cyclooxygenase- 2 in cell proliferation and cell death in human malignancies. Int J Cell Biol. 2010. doi: $10.1155 / 2010 / 215158$.

9. Steinbach G, Lynch PM, Phillips RK, Wallace MH, Hawk E, Gordon $\mathrm{GB}$, et al. The effect of celecoxib, a cyclooxygenase-2 inhibitor, in familial adenomatous polyposis. New Engl J Med. 2000; 342:1946-1952.

10. Rahme E, Barkun AN, Toubouti Y, Bardou M. The 
cyclooxygenase-2-selective inhibitors rofecoxib and celecoxib prevent colorectal neoplasia occurrence and recurrence. Gastroenterol. 2003; 125:404-412.

11. Tsioulias GJ. NSAIDs and Colorectal Cancer Control: Promise and Challenges. Curr Pharmacol Rep. 2015; 1(5): 295-301. doi: 10.1007/s40495-015-0042-x.

12. Pyrko P, Soriano N, Kardosh A, Liu YT, Uddin J, Petasis NA, et al. Downregulation of survivin expression and concomitant induction of apoptosis by celecoxib and its non-cyclooxygenase2- inhibitory analog, dimethyl-celecoxib (DMC), in tumor cells in vitro and in vivo. Mol Cancer. 2006; 5:19.

13. Smigel K. Arthritis drug approved for polyp prevention blazes trail for other prevention trials. J Natl Can Inst. 2000; 92(4):297299. doi.org/10.1093/jnci/92.4.297.

14. Kim B. Giardiello FM. Chemoprevention in familial adenomatous polyposis. Best Pract Res Clin Gastroenterol. 2011; 25:607-622. doi: 10.1016/j.bpg.2011.08.002.

15. Arber N, Eagle CJ, Spicak J, Racz I, Dite P, Hajer J, Zavoral M, Lechuga MJ, Gerletti P, Tang J, Rosenstein RB, Macdonald K, Bhadra P, Fowler R, Wittes J, Zauber AG, Solomon SD, Levin B. Celecoxib for the prevention of colorectal adenomatous polyps. New Eng J Med. 2006; 355:885-895.

16. De Vecchis R, Baldi C, Di Biase G, Ariano C, Cioppa C, Giasi A, Valente L, Cantatrione S. Cardiovascular risk associated with celecoxib or etoricoxib: A meta-analysis of randomized controlled trials which adopted comparison with placebo or naproxen. Minerva Cardioangiol. 2014; 62:437-448.

17. Wilczewska AZ, Niemirowicz K, Markiewicz KH, Car H. Nanoparticles as drug delivery systems. Pharmacol Rep. 2012; 64:1020-1037.

18. Patra JK, Das G, Fraceto LF, Campos EVR, Rodriguez-Torres MDP, Acosta-Torres LS, et al. Nano based drug delivery systems: recent developments and future prospects. J

Nanobiotechnol. 2018; 16:71. doi:10.1186/s12951-018-0392-8.

19. Hans ML, Lowman AM. Biodegradable nanoparticles for drug delivery and targeting. Curr Opin Solid St M Sci. 2002; 6(4):319327.

20. Al-Saidan SM, Krishnaiah YSR, Patro, S. et al. In vitro and in vivo evaluation of guar gum matrix tablets for oral controlled release of water-soluble diltiazem hydrochloride. AAPS PharmSciTech. 2005; 6:E14. doi.org/10.1208/pt060105.

21. Sinha V, Mittal BR, Bhutani KK, Kumria R. Colonic drug delivery of 5-fluorouracil: An in vitro evaluation. Int J pharma. 2004; 269:101-108. doi.10.1016/j.ijpharm.2003.09.036.

22. Mudgil D, Barak S, Patel A, Shah N. Partially hydrolyzed guar gum as a potential prebiotic source. Int. J. Bio. Macromol. 2018; 112:207-10.

23. Thombare N, Jha U, Mishra S, Siddiqui MZ. Guar gum as a promising starting material for diverse applications: A review. Int J Biol Macromol. 2016; 88: 361-72.
24. Krishnaiah YS, Karthikeyan RS, Gouri Sankar V, Satyanarayana V. Three-layer guar gum matrix tablet formulations for oral controlled delivery of highly soluble trimetazidine dihydrochloride. J Control Release. 2002; 81(1-2):45-56.

25. Sarmah JK, Mahanta R, Bhattacharjee SK, Mahanta R, Biswas A. Controlled release of tamoxifen citrate encapsulated in crosslinked guar gum nanoparticles. Int J Bio Macromol. 2011; 49:390-96.

26. Chaurasia, Mohini \& Chourasia, Manish \& Jain, Nitin \& Jain, Aviral \& Soni, Vandana \& Gupta, Yashwant \& Jain, Sanjay. Cross-linked guar gum microspheres: A viable approach for improved delivery of anticancer drugs for the treatment of colorectal cancer. AAPS PharmSciTech. 2006; 7(74). doi.10.1208/pt070374.

27. Sarmah JK, Bhattacharjee SK, Mahanta R, Mahanta R. Preparation of cross-linked guar gum nanospheres containing tamoxifen citrate by single step emulsion in situ polymer cross-linking method. J Incl Phenom Macrocycl Chem. 2009; 65: 329-34. doi: 10.1007/s10847-009-9589-7.

28. Yuan H, Chen CY, Chai GH, Du YZ, Hu FQ. Improved transport and absorption through gastrointestinal tract by PEGylated solid lipid nanoparticles. Mol. Pharm. 2013;10: 1865-73.

29. Fan H, Liu G, Huang Y, Li Y, Xia Q. Development of a nanostructured lipid carrier formulation for increasing photostability and water solubility of phenylethyl resorcinol. Appl. Surf. Sci. 2014; 288: 193-200.

30. Saha RN, Sajeev C, Jadhav PR, Patil SP, Srinivasan N. Determination of celecoxib in pharmaceutical formulations using UV spectrophotometry and liquid chromatography. Journal of Pharmaceutical and Biomedical Analysis. 2002; 28 741-751.

31. Tyle P. Controlled drug delivery: Fundamentals and applications. Robinson JR, Lee VHL. Dekker M. Editors. Inc., New York. 1987. 739 ISBN 0-8247-7588-0. doi.org/10.1002/jps.2600770119

32. Higuchi T. Mechanism of sustained-action medication. Theoretical analysis of rate of release of solid drugs dispersed in solid matrices. J Pharm Sci. 1963; 52(12):1145-49. doi.org/10.1002/jps.2600521210.

33. Korsmeyer RW, Gurny R, Doelker E, Buri P, Peppas NA. Mechanisms of solute release from porous hydrophilic polymers. Int J Pharm. 1983;15(1): 25-35.

34. Mosmann T. Rapid colorimetric assay for cellular growth and survival: application to proliferation and cytotoxicity assays. $J$ Immunol Methods. 1983; 65(1):55-63. doi: 10.1016/00221759(83)90303-4.

35. Clogston JD, Patri AK. Zeta potential measurement. Methods Mol Biol. 201; 697:63-70. doi: 10.1007/978-1-60327-198-1_6.

36. Mudgil D, Barak S, Khatkar BS. X-ray diffraction, IR spectroscopy and thermal characterization of partially hydrolyzed guar gum. Int J Bio Macromol. 2012; 50:1035-39. 